\title{
Lung Metastasis Occurring 12 Years after Colonic Cancer Surgery
}

\author{
Kozo Ikuta ${ }^{1}$, Hiroaki Hirakawa ${ }^{1}$, Miki Ikeuchi ${ }^{2}$ and Seiji Shio ${ }^{1}$
}

Key words: colonic cancer, late recurrence

(Intern Med Advance Publication)

(DOI: 10.2169/internalmedicine.8054-21)

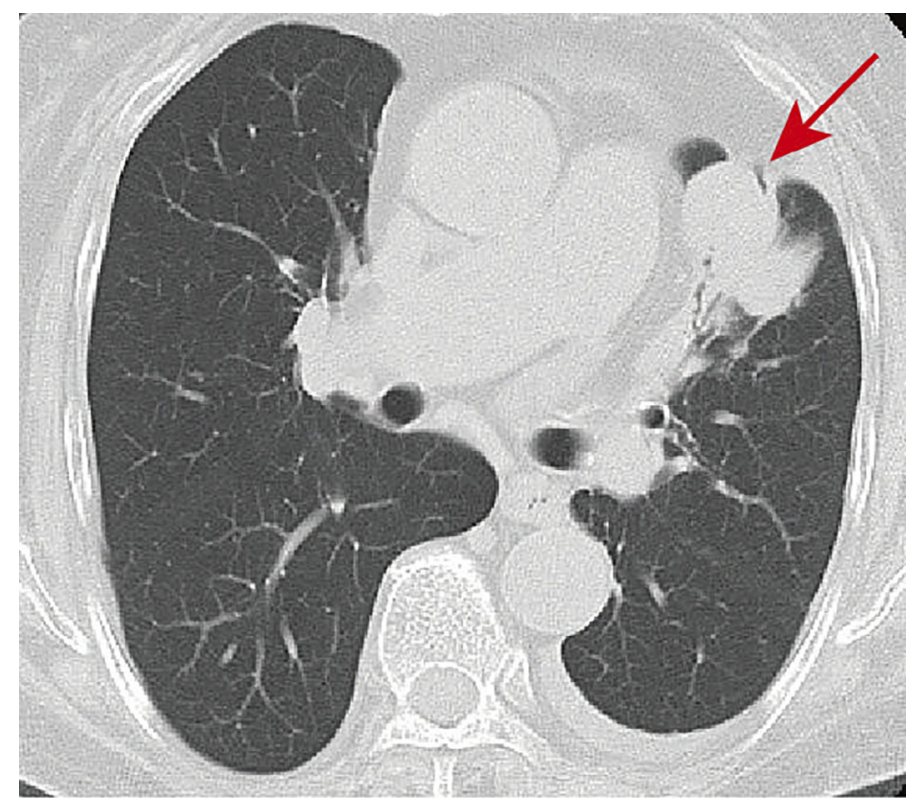

Picture 1.

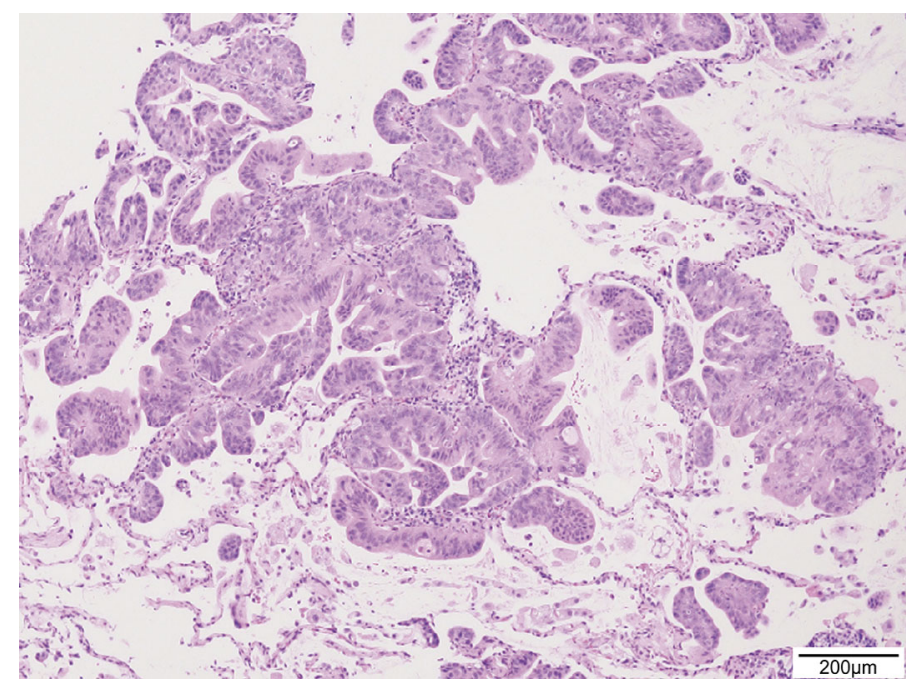

Picture 2.

${ }^{1}$ Division of Gastroenterology, Shinko Memorial Hospital, Japan and ${ }^{2}$ Department of Respiratory Center, Shinko Memorial Hospital, Japan Received: May 31, 2021; Accepted: September 15, 2021; Advance Publication by J-STAGE: November 6, 2021 Correspondence to Dr. Kozo Ikuta, kikuta@kuhp.kyoto-u.ac.jp 


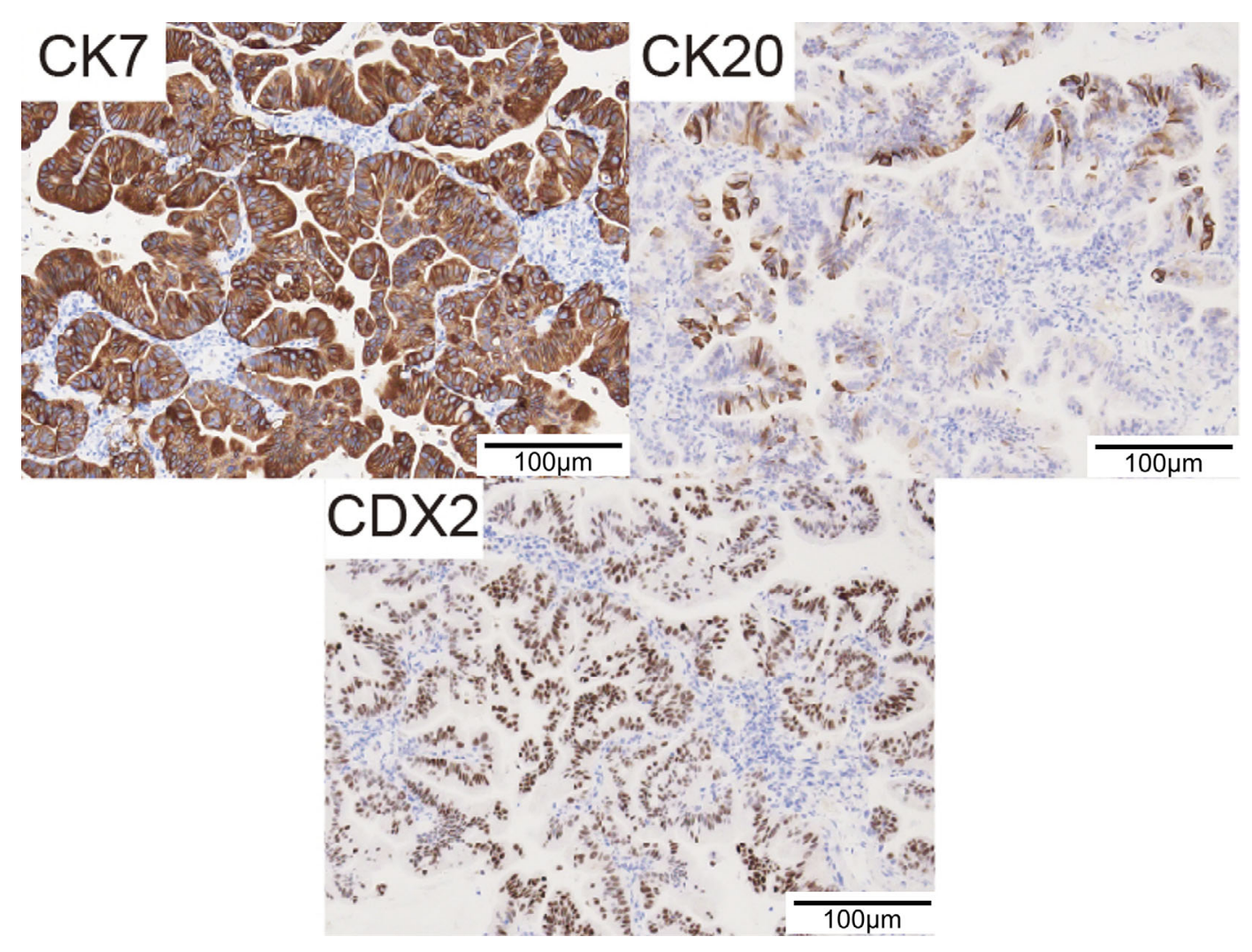

Picture 3.

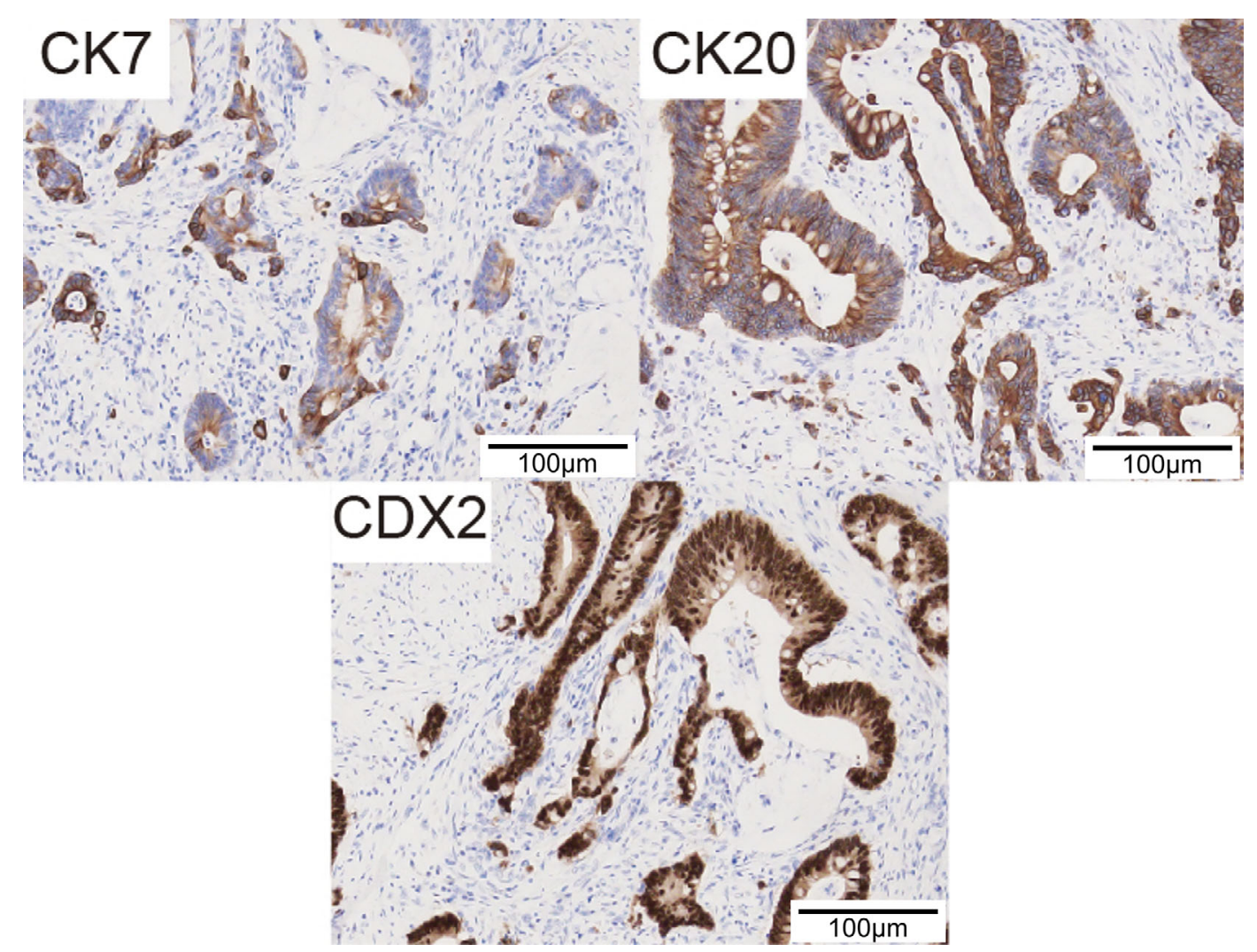

Picture 4.

A 71-year-old woman underwent ascending colonic cancer surgery (Stage II, R0 resection) followed by postoperative chemotherapy. No recurrence was observed for five years after the operation. At 83 years old, she complained of dyspnea. Computed tomography showed a 44-mm tumorous lesion in the left lung with pleural effusion (Picture 1). 
Systemic examinations, including colonoscopy, did not reveal any neoplastic lesions other than the lung lesion. A transbronchial lung biopsy revealed adenocarcinoma (Picture 2). Immunohistochemistry for the specimens showed CK7 (+)/CK20 (+)/CDX2 (+) (Picture 3). These findings were atypical for primary lung adenocarcinoma. Immunohistochemistry for resected colonic specimens showed CK7 (+)/ CK20 (+)/CDX2 (+) (Picture 4), which was not typical for primary colonic cancer. We diagnosed the lung tumor as metastasis of colonic cancer. In many cases, colonic cancer recurs within five years after surgery $(1,2)$ We herein report a case of recurrence of colonic cancer in the lung 12 years after R0 surgery.
The authors state that they have no Conflict of Interest (COI).

\section{References}

1. Raul Caso, Anne Fabrizio, Michael Sosin. Prolonged follow-up of colorectal cancer patients after 5 years: to follow or not to follow, that is the question (and how)! Ann Transl Med 8: 164, 2020.

2. Seok In Seo, Seok-Byung Lim, Yong Sik Yoon, Chan Wook Kim, Chang Sik Yu, TaeWon Kim, et al. Comparison of recurrence patterns between $\leq 5$ years and $>5$ years after curative operations in colorectal cancer patients. J Surg Oncol 108: 9-13, 2013.

The Internal Medicine is an Open Access journal distributed under the Creative Commons Attribution-NonCommercial-NoDerivatives 4.0 International License. To view the details of this license, please visit (https://creativecommons.org/licenses/ by-nc-nd/4.0/).

(C) The Japanese Society of Internal Medicine Intern Med Advance Publication 